\title{
Is the solubilized product from the degradation of lignocellulose by actinomycetes a precursor of humic substances?
}

\author{
Carlos Trigo and Andrew S. Ball \\ Author for correspondence: Carlos Trigo. Tel: +4420687 3332. Fax: +44 20687 3416. e-mail: \\ neryt@essex.ac.uk
}

Department of Biology, University of Essex, Wivenhoe Park, Colchester CO4 3SQ, UK

\begin{abstract}
Three actinomycetes (Streptomyces Sp. EC22, Streptomyces viridosporus T7A and Thermomonospora fusca BD25) were assessed for their ability to degrade ball-milled wheat straw. All gave maximum levels of solubilized lignocellulose products (APPL) at the beginning of the stationary phase of growth (72-96 h). Low-molecular-mass aromatic compounds extracted from the APPL were analysed by reverse-phase and gas chromatography. Although the number of chromatographic peaks detected made identification of the products difficult, p-coumaric acid (4-hydroxycinnamic acid), protocatechuic acid (3,4dihydroxybenzoic acid), gallic acid (3,4,5-trihydroxybenzoic acid), gallic acid methyl ester (methyl-3,4,5-trihydroxybenzoate) and 4-methoxyphenol were recognized. The infrared spectra of the three strains were similar to the spectra of humic acids, with all APPL extracts showing carbonyl, amino, carboxyl, aliphatic and aromatic group vibrations. Also detected were peptide linkages of proteins. The results suggest a role for actinomycetes in the formation of humic substances in soils and composts.
\end{abstract}

Keywords: actinomycetes, acid-precipitable polymeric lignin, humic substances, lignocellulose degradation

\section{INTRODUCTION}

Lignocellulose, the main component of wheat straw, is composed of three polymers; lignin (10-30\%, dry wt), cellulose (25-45\%, dry wt) and hemicellulose (24-50\%, dry wt) (Betts et al., 1992). Cellulose is the most abundant natural compound in nature. It is a homopolymer of glucose linked by $\beta$-1,4-glycosidic bonds. Unlike cellulose, hemicellulose is a non-linear heteropolymer composed mainly of xylose but also containing other carbohydrates such as galactose, mannose, arabinose, glucuronic acid, rhamnose and fucose linked together predominantly by $\beta$ 1,4-glycosidic bonds. These two polymers are physically encrusted with lignin, to which they are covalently linked through lignin-saccharide bonds that provide mechanical strength and rigidity to plant tissues. In plant cell walls, monophenolic compounds such as $p$-coumaric and ferulic acids are known to link arabinoxylans to lignin via ester bonds (Shibuya, 1984; Gubler et al., 1985; Nishitani \& Nevins, 1988). Lignin is synthesized in plants from coniferyl and coumaryl alcohols through radical coupling

Abbreviation : APPL, solubilized lignocellulose products. mediated by plant peroxidases. This random chemical coupling results in a complex three-dimensional phenolic polymer with a variety of bonding arrangements giving aryl glycerol- $\beta$-aryl ether, non-cyclic benzyl aryl ether, biphenyl, diphenylether, phenylcoumaran, 1,2-diarylpropane and other such structures (Crawford, 1981). As a result of this molecular complexity accentuated by covalent attachment to other plant polymers (e.g. cellulose and hemicellulose), lignin decomposition is the ratelimiting factor for the biological and chemical degradation of lignocellulose materials.

In natural terrestrial habitats (e.g. soils and composts), lignin is degraded by a complex microflora which includes both eukaryotic and prokaryotic organisms, such as white-rot fungi and actinomycetes, respectively. Most studies on the processes involved in lignin degradation have used the white-rot fungus Phanerochaete chrysosporium, because of the high ligninolytic activities which it exhibits. Mineralization of lignin by white-rot fungi is an established enzymic process which occurs during the secondary phase of growth under conditions of nitrogen or carbon starvation and is mediated by a number of different enzymes, of which lignin peroxidases and $\mathrm{Mn}^{2+}$ 
dependent peroxidases are the most important (for a review, see Kirk \& Farrel, 1987).

Actinomycetes are another group of organisms that can degrade lignin materials, although little is known about their lignocellulose-degrading mechanisms (Vicuna, 1988). Actinomycetes are Gram-positive bacteria which can be found on almost every natural substrate including soils and composts, fresh water basins, foodstuffs and the atmosphere (Waksman, 1967). Their hyphal growth is well suited for the colonization of plant biomass and they secrete a range of enzymes active against lignocellulose (McCarthy \& Ball, 1991). Research on the biodegradation of lignin by actinomycetes has focused on the screening and detection of good lignocellulose degraders (Crawford, 1978; Crawford et al., 1983; McCarthy \& Broda, 1984; Ball \& McCarthy, 1988; Ball et al., 1989; Trigo \& Ball, 1994). Even so, bacterial rates of lignin degradation compare poorly with the white-rot fungus $P$. chrysosporium. By following ${ }^{14} \mathrm{CO}_{2}$ evolution from the degradation of $\left[{ }^{14} \mathrm{C}\right]$ lignin-labelled lignocellulose, McCarthy and co-workers could detect, in a number of actinomycetes, less than $10 \%$ lignin mineralization to $\mathrm{CO}_{2}$ compared to $50 \%$ for $P$. chrysosporium (McCarthy \& Broda, 1984; McCarthy et al., 1984). This difference in lignin degradation rates between fungi and bacteria is probably due to different strategies of lignin degradation developed by these two groups of micro-organisms. Although lignin degradation by both bacteria and fungi is an enzymic process, bacterial degradation results in solubilization rather than depolymerization and mineralization of lignocellulose (McCarthy, 1987). The primary product from the degradation of straw by actinomycetes is a soluble high-molecular-mass, lignocarbohydrate complex (APPL) (Crawford et al., 1983; Borgmeyer \& Crawford, 1985; McCarthy et al., 1986; Pometto \& Crawford, 1986).

Crawford et al. (1983) first reported APPL production in culture supernatants of Streptomyces viridosporus T7A. While ${ }^{14} \mathrm{C}$ isotopic techniques confirmed the lignin origin of APPL (McCarthy et al., 1986), other analyses showed chemical differences between APPL of inoculated cultures and uninoculated control samples (Crawford et al., 198.3). These differences included an increase in the number of phenolic hydroxyl and carboxyl groups in APPL, suggesting oxidative cleavage of $p$-hydroxy ether linkages and methoxyl groups in the lignin structure (Crawford $e t$ al., 1983). Additional hydroxyl and carboxyl groups were also detected in APPL from Streptomyces sp. EC1 (Ball et al., 1990). Analysis of APPL by solid-state ${ }^{13} \mathrm{C}-\mathrm{NMR}$ spectroscopy (McCarthy et al., 1986) showed an increase in carbonyl groups. Although McCarthy et al. (1986) found no solubilization of radiolabelled lignocellulose by Thermomonospora mesopbila and Streptomyces cyaneus (suggesting that APPL was an end-product), Crawford and coworkers showed that $S$. viridosporus T7 A, Streptomycesbadius and the eukaryotic lignin-degrader $P$. chrysosporium could significantly degrade APPL produced by $S$. viridosporus T7A. Among the products formed by these organisms were $p$-coumaric acid (4-hydroxycinnamic acid), ferulic acid (4-hydroxy-3-methoxycinnamic acid), p-hydroxy- benzoic acid, $p$-hydroxybenzaldehyde, protocatechuic acid (3,4-dihydroxybenzoic acid), vanillic acid (4hydroxy-3-methoxybenzoic acid) and vanillin (4-hydroxy3-methoxybenzaldehyde) (Pometto \& Crawford, 1986). In addition, syringic acid (3,5-dimethoxy-4-hydroxybenzoic acid), ferulic acid (4-hydroxy-3- methoxycinnamic acid), vanillin and vanillic acid were detected in culture supernatants of Streptomyces sp. EC1 (Godden et al., 1992). These data suggest that APPL is not simply an endproduct but can be further modified. Furthermore, HPLC analysis of extracts from APPL in culture supernatants obtained at different times from Streptomyces sp. EC1 growing on wheat straw showed that modifications of APPL do occur during growth of the organism (Ball et al., 1990).

The work described above is not conclusive regarding the fate of APPL in culture supernatants. These studies were carried out in vitro. In natural habitats, production of APPL by actinomycetes may be part of a more complex process, with other bacteria and fungi using APPL as substrates. In natural environments, APPL may serve as an intermediate in the formation of humic substances in soils and composts (Donnelly \& Crawford, 1988; Senesi et al., 1987; Fustec et al., 1989). Humic substances are not defined in specific chemical terms, but as the fraction of organic matter that is not soluble in water at $\mathrm{pH}<2$ but soluble at neutral and alkaline $\mathrm{pH}$ (Amalfitano et al., 1992). In natural terrestrial environments, several enzymes, including phenoloxidases and peroxidases, have been found associated with humic substances through covalent and hydrogen bonds (Martin \& Haider, 1980; Suflita \& Bollag, 1980; Sjoblad \& Bollag, 1981). Similarly, Ball et al. (1990) detected veratryl alcohol and peroxidase activities in the APPL fraction extracted from supernatants of Streptomyces sp. EC1. The association of proteins with lignocellulose degraded products results in protection of the tertiary structure of proteins, which increases resistance to long term denaturation. (Skujins \& McLaren, 1969; Pettit et al., 1977). This long term action of native enzymes may meet the requirements for lignin degradation.

In this work we describe the characterization of APPL during growth on wheat straw of three previously used (Trigo \& Ball, 1994) lignocellulolytic actinomycetes, and examine the relationship between APPL and humic substances.

\section{METHODS}

Organisms and growth conditions. Three strains of selected mesophilic and thermophilic actinomycetes were used: Streptomyces sp. EC22 (thermophilic), Streptomyces viridosporus T7A (mesophilic) and Thermomonospora fusca BD25 (thermophilic). They were obtained from W. Amner, University of Liverpool, D. L. Crawford, University of Idaho and A. J. McCarthy, University of Liverpool, respectively, and were maintained as suspensions of spores in $20 \%(\mathrm{v} / \mathrm{v})$ glycerol at $-20^{\circ} \mathrm{C}$. Distilled water suspensions of sporulating growth on L-agar plates (Hopwood et al., 1985) were used to inoculate shake flasks containing basal salts medium and $0.6 \%(\mathrm{w} / \mathrm{v})$ yeast extract (McCarthy \& Broda, 1984) supplemented with $0 \cdot 2 \%(\mathrm{w} / \mathrm{v})$ 
ball-milled wheat straw. After inoculation, cultures were incubated at 37 or $50^{\circ} \mathrm{C}$ with shaking at 200 r.p.m.

Measurement of acid precipitated polymer of lignin (APPL). Lignocarbohydrate solubilizing activity was determined by acidifying culture supernatants to $\mathrm{pH} 1-3$ with $\mathrm{HCl}$. The amount of APPL present was measured by recording the increase in absorbance at $600 \mathrm{~nm}$ over a $5 \mathrm{~min}$ period following acidification (Ball et al., 1990; Trigo \& Ball, 1994).

Extraction and analysis of APPL. Supernatants $(100 \mathrm{ml})$ were acidified to $\mathrm{pH} \mathrm{1-3}$ with $\mathrm{HCl}$. After a $30-60 \mathrm{~min}$ interval, the APPL. was extracted twice with ethyl acetate $(40 \mathrm{ml})$ and once with ethyl ether $(40 \mathrm{ml})$. The organic extracts were evaporated overnight (Pometto \& Crawford, 1990).

(i) Reverse-phase chromatography. Low-molecular-mass organicsoluble compounds were extracted from APPL by leaching the sample with $500 \mu \mathrm{l} 10 \%(\mathrm{v} / \mathrm{v})$ acetonitrile in water. Following clarification by centrifugation, these solutions were chromatographed in a Beckman HPLC system composed of a programmable solvent module (Module 126) and a scanning detector (Module 167) equipped with a reverse-phase column (25 $\mathrm{cm} \times 4.6 \mathrm{~mm}$ i.d.) of Spherisorb ODS2 (Anachem) and a $20 \mu \mathrm{l}$ injection loop. The mobile phase was a gradient of acetonitrile in water adjusted to $\mathrm{pH} 1-3$ with $\mathrm{H}_{2} \mathrm{SO}_{4}$. The acetonitrile concentration in the mobile phase started at $10 \%$ $(\mathrm{v} / \mathrm{v})$, increased to $50 \%(\mathrm{v} / \mathrm{v})$ over $2 \mathrm{~min}$ and then to $100 \%$ $(\mathrm{v} / \mathrm{v})$ acetonitrile over the following $10 \mathrm{~min}$. The flow-rate was $0.8 \mathrm{ml} \mathrm{min}{ }^{-1}$. Peaks were scanned for their UV spectra, and their retention time was recorded. Their spectral properties were compared to the standard compounds gallic acid, protocatechuic acid, p-coumaric acid (Sigma), 4-methoxyphenol and 2,6dimethoxyphenol (Aldrich).

(ii) Gas-chromatography. The following procedure was used to extract low-molecular-mass organic-soluble compounds from APPL fractions: samples were derivatized with $300 \mu$ l dioxane, $20 \mu \mathrm{l}$ pyridine and $10 \mathrm{mg}$ trimethylsilylacetamide (TMSA, Sigma) for $2 \mathrm{~h}$ at $37^{\circ} \mathrm{C}$. After centrifugation to clarify the reaction mixture, samples $(1 \mu \mathrm{l})$ were injected in a HewlettPackard 5890 gas chromatograph with a flame ionization detector and an OV-1 capillary column $(30 \mathrm{~m} \times 0.32 \mathrm{~mm})$. The oven temperature was maintained at $120^{\circ} \mathrm{C}$ for $5 \mathrm{~min}$, followed by a $10^{\circ} \mathrm{C} \mathrm{min}^{-1}$ gradient to 260 and $280^{\circ} \mathrm{C}$. The carrier gas was helium.

Aromatic compounds extracted from APPL fractions were identified by comparing their retention times with 12 standard compounds ( $p$-coumaric acid, ferulic acid, protocatechuic acid, gallic acid, gallic acid methyl ester, caffeic acid, syringic acid (Sigma), acetovanillone, 3,5-dimethoxybenzoic acid, 2,6dimethoxyphenol, isovanillic acid (3-hydroxy-4-methoxybenzoic acid) and 4-methoxyphenol (Aldrich).

(iii) IR spectroscopy. Infrared spectra of the APPL fractions were recorded for the wavelength range $4000-600 \mathrm{~cm}^{-1}$ with a Perkin-Elmer infrared spectrophotometer model 1576. Samples were prepared by mixing with $\mathrm{KBr}$ and compressing the mixture into a disc (Kendall, 1966).

\section{RESULTS AND DISCUSSION}

\section{Analysis of extracted solubilized degradation product from the growth of actinomycetes on wheat straw}

During growth up to stationary phase, Streptomyces viridosporus T7A, Streptomyces sp. EC22 and Thermomonospora fusca $\mathrm{BD} 25$ produced APPL on ball-milled wheat straw. Maximum levels of APPL were recorded at the beginning of the stationary phase (72-96 h) for all the strains examined (data not shown). Although all strains were able to solubilize straw, $T$. fusca $\mathrm{BD} 25$ produced the highest levels of APPL $\left(\mathrm{OD}_{600}=0 \cdot 11\right)$. To investigate the composition and the variability of the solubilized product, APPL from the three strains was harvested after 72-96 h and low-molecular-mass organic-soluble compounds were extracted. These compounds were separated by reverse-phase HPLC and gas-chromatography. The HPLC chromatographic profiles of APPL produced by the three actinomycetes are shown in Fig. 1. All three strains were capable of solubilizing lignocellulose material in excess of the control (uninoculated flask). However the chromatographic profiles of the organisms examined were distinct. Although the intensities of chromatographic peaks for APPL extracts from the three strains were different, most peaks eluted between 2.5 and $9.0 \mathrm{~min}$. The differences in chromatographic profiles may support the view that lignin is degraded by different mechanisms in different species of actinomycetes (Borgmeyer \& Crawford, 1985; Mason, 1988).

UV spectra of the major peaks obtained during chromatography of compounds extracted from the APPL of each actinomycete and the peaks' retention times, were compared with those of commercially available standards. Only the product with a retention time of $2.8 \mathrm{~min}$ was found in cultures of all three strains; this was not identified. Although most of the other products were unique to each actinomycete strain, $p$-coumaric acid (retention time $7.9 \mathrm{~min}$ ) was identified in $T$. fusca BD25 and S. viridosporus T7A. Also, gallic acid (retention time $5.7 \mathrm{~min}$ ) was identified in Streptomyces sp. EC22 (Table 1). Analysis of the solubilized products present in APPL was also performed by gas-chromatography. Chromatographic profiles of the extracts from APPLs of the three strains showed an increase in the number of peaks compared to the control (uninoculated flask) (Fig. 2). Although most of the peaks on chromatograms were not conclusively identified, some of them matched the retention times of the standards used. On the basis of retention times, 4-methoxyphenol (retention time $1.48 \mathrm{~min}$ ) was present in extracts of APPL from all strains, as were protocatechuic acid (retention time $9 \cdot 86 \mathrm{~min}$ ), 2,4dimethoxybenzoic acid (retention time $7.72 \mathrm{~min}$ ) and gallic acid methyl ester (retention time $10.76 \mathrm{~min}$ ). Table 1 summarizes the compounds detected. Several aromatic products of straw degradation, including $p$-coumaric acid, were previously detected in Streptomyces sp. EC1 (Godden et al., 1992), Streptomyces badius, Streptomyces setonii and $S$. viridosporus T7A (Pometto \& Crawford, 1986). Esterified $p$-coumaric acid comprises a high percentage of the total weight of lignocellulose materials and is associated with lignin through ester linkages to the terminal $\gamma$-carbon of the phenylpropanoid unit of lignin (Shimada, 1972). These results favour the idea suggested by Pometto \& Crawford that APPL is an intermediate that is further degraded to polymeric aromatic units, rather than the view that APPL is an end-product of a process by which cellulolytic and hemicellulolytic enzymes gain access to plant polysaccharides (Crawford et al., 1984). 


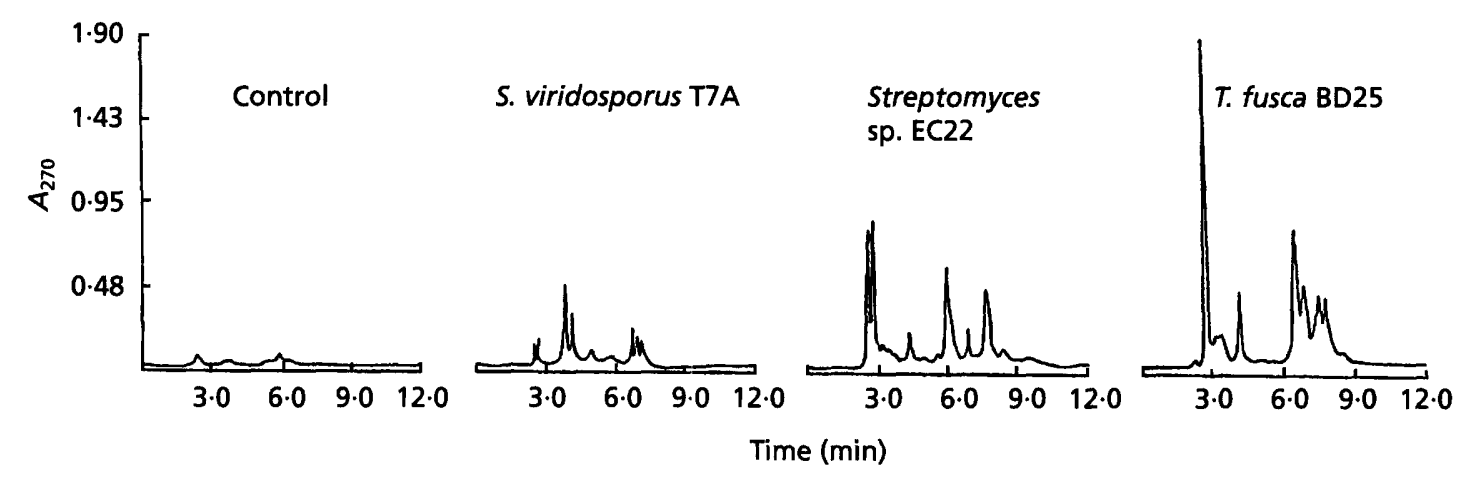

Fig. 1. HPLC reverse-phase chromatograms of low-molecular-mass organic-soluble extracts from APPL recorded at $270 \mathrm{~nm}$ after 72-96 h of growth for S. viridosporus T7A, Streptomyces sp. EC22 and T. fusca BD25.

Table 1. Compounds identified by HPLC and gas-chromatographic analysis of solubilized fractions from selected actinomycete strains

(T) Denotes thermophile; + indicates product was present in the chromatographic profile;

- indicates product was absent from the cromatographic profile.

\begin{tabular}{|c|c|c|c|c|}
\hline Structural formula & Standard compound & $\begin{array}{c}\text { Streptomyces } \\
\text { sp. EC22 } \\
\text { (T) }\end{array}$ & $\begin{array}{c}\text { S. viridosporus } \\
\text { T7A }\end{array}$ & $\begin{array}{c}T . \text { fusca } \\
\text { BD25 (T) }\end{array}$ \\
\hline & $p$-Coumaric acid & - & $t^{*}$ & $+^{*}$ \\
\hline & $\begin{array}{l}\text { Protocatechuic } \\
\text { acid }\end{array}$ & + & - & - \\
\hline & Gallic acid & $+^{*}$ & - & - \\
\hline & $\begin{array}{l}\text { Gallic acid methyl } \\
\text { ester }\end{array}$ & + & + & - \\
\hline & $\begin{array}{l}\text { 2,4-Dimethoxy } \\
\text { benzoic acid }\end{array}$ & + & + & - \\
\hline & 4-Methoxyphenol & + & + & + \\
\hline
\end{tabular}

*'The product was identified by reverse-phase HPLC. All other products were identified by gaschromatography. 


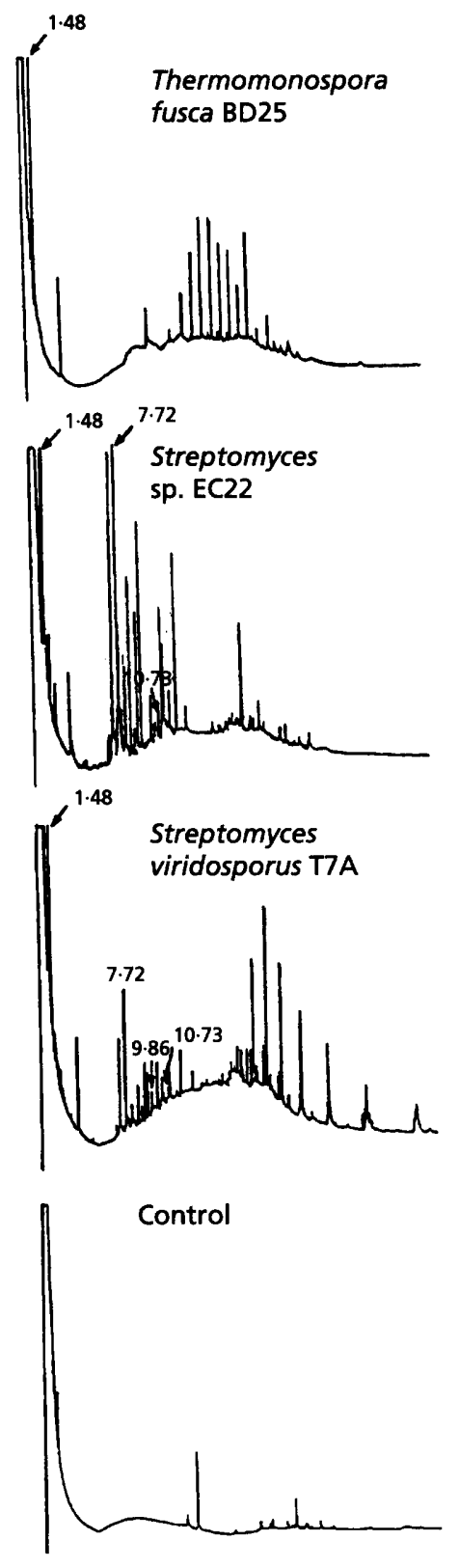

Fig. 2. Gas-chromatography analysis of low-molecular-mass organic-soluble extracts from APPL for $S$. viridosporus T7A, Streptomyces sp. EC22 and T. fusca BD25. Peaks identified on the basis of their retention times $(\mathrm{min})$ are indicated $(1.48,4-$ methoxyphenol; 7.72, 2,4-dimethoxybenzoic acid; 9.86, protocatechuic acid; 10.76 , gallic acid methyl ester).

\section{Qualitative changes in the solubilized product during growth and solubilization of straw by $T$. fusca BD25}

To examine changes in APPL during growth of T. fusca BD25 on ball-milled wheat straw, samples of APPL were taken from cultures at regular intervals. The composition of low-molecular-mass organic-soluble compounds was determined by HPLC (Fig. 3). After $3 \mathrm{~d}$ growth, significant amounts of aromatic material were present in APPL extracts. After $6 \mathrm{~d}$ incubation, the composition of these extracts showed distinct changes. After $9 \mathrm{~d}$ the composition of the APPL extracts stabilized and remained unchanged during the following $7 \mathrm{~d}$ incubation. Similar results were obtained with APPL from $S$. viridosporus and S. badius (Borgmeyer \& Crawford, 1985). Streptomyces sp. EC1 also changed in chromatographic profile when sampled at intervals during growth (Ball et al., 1990). The latter authors suggested that depolymerization-polymerization occurs implying that APPL could serve as an intermediate in the formation of humic substances in composts.

\section{Infrared spectroscopy analysis}

Infrared spectral analysis of APPL from actinomycete culture supernatants (Fig. 4) showed considerable similarity between the products from the three strains. The spectra of all preparations displayed a strong band at $3400-3200 \mathrm{~cm}^{-1}$, probably due to stretching vibrations of $\mathrm{H}$-bonded $\mathrm{OH}, \mathrm{COOH}$ and $\mathrm{NH}_{2}$ groups (Stevenson \& Goh, 1971). In the case of T. fusca BD25, this band is shifted towards a lower wave number, perhaps reflecting the increased presence of $\mathrm{H}$-bonded $\mathrm{OH}$ and $\mathrm{NH}_{2}$ groups in the humic-type APPL polymers (Senesi et al., 1987). Common to these three spectra were weak bands at $1740-1710 \mathrm{~cm}^{-1}$ attributed to numerous $\mathrm{C}=\mathrm{O}$ containing groups (Russel et al., 1983). Aliphaticity is shown by bands at $2850 \mathrm{~cm}^{-1}$ (aliphatic $\mathrm{C}-\mathrm{H}$ stretch) and 1430 (aliphatic C-H deformation) and $1000 \mathrm{~cm}^{-1}$ (skeletal vibration of aliphatics) (Senesi et al., 1987). A broad band of medium intensity at $1660 \mathrm{~cm}^{-1}$ and small bands at $1530-1510 \mathrm{~cm}^{-1}$, shown by all three spectra, can be attributed to the peptide linkage in proteins (Stevenson \& Goh, 1971; Filip et al., 1974; Russel et al., 1983), supporting previous reports that proteins are bound to APPL (Ball et al., 1990). Also, there is evidence of adsorption of active enzymes to humic substances (Claus \& Philip, 1988). Generally, the spectra from all APPL preparations showed a high degree of similarity with spectra of humic substances (Boyd et al., 1979; Russel $e t$ al., 1983; Senesi et al., 1987), consistent with suggestions that actinomycetes contribute to humification (Ball et al., 1990; McCarthy et al., 1986).

In conclusion, the three strains examined were able to grow and solubilize ball-milled wheat straw. Further, the solubilized product from all three strains contained aromatic monomers, such as $p$-coumaric acid, protocatechuic acid, gallic acid, gallic acid methyl ester, 2,4dimethoxybenzoic acid and 4-methoxyphenol. Phenolic acids are considered to play a major role in humification in soils (Morita, 1965; Katase, 1981). In fact, humic substances are predominantly formed by humic acid polymers which are synthesized from phenolic acids, amino acids and other large molecules through enzymic and oxidative reactions (Felbeck, 1971; Haider et al., 1975; Martin \& Haider 1980). Oxidative polymerization is thought to be mediated by phenoloxidases and peroxidases through the formation of phenoxy-radicals which are converted to stable compounds by self- or cross-coupling to other molecules (Bollag et al., 1980, 1981; Martin \& Haider, 1980). Production of extracellular peroxidase is common 


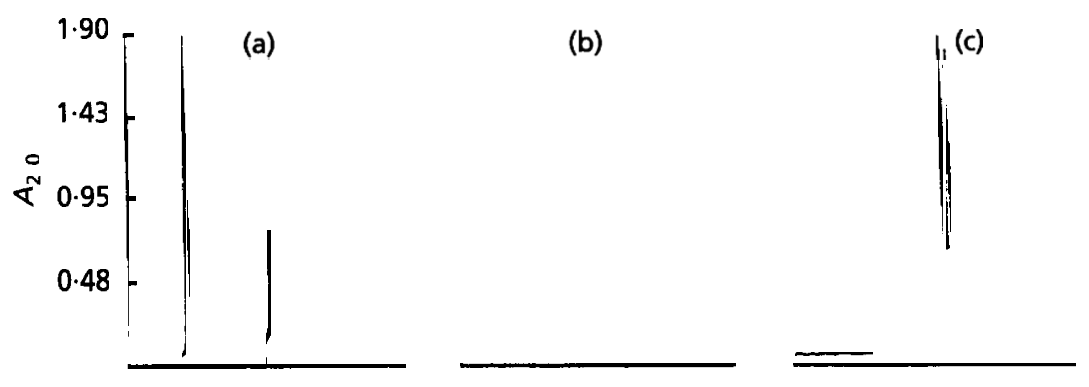

Fig. 3. HPLC reverse-phase chromatograms of solubilized low-molecular-mass organicsoluble extracts from APPL from culture supernatants of $T$. fusca BD25 grown on

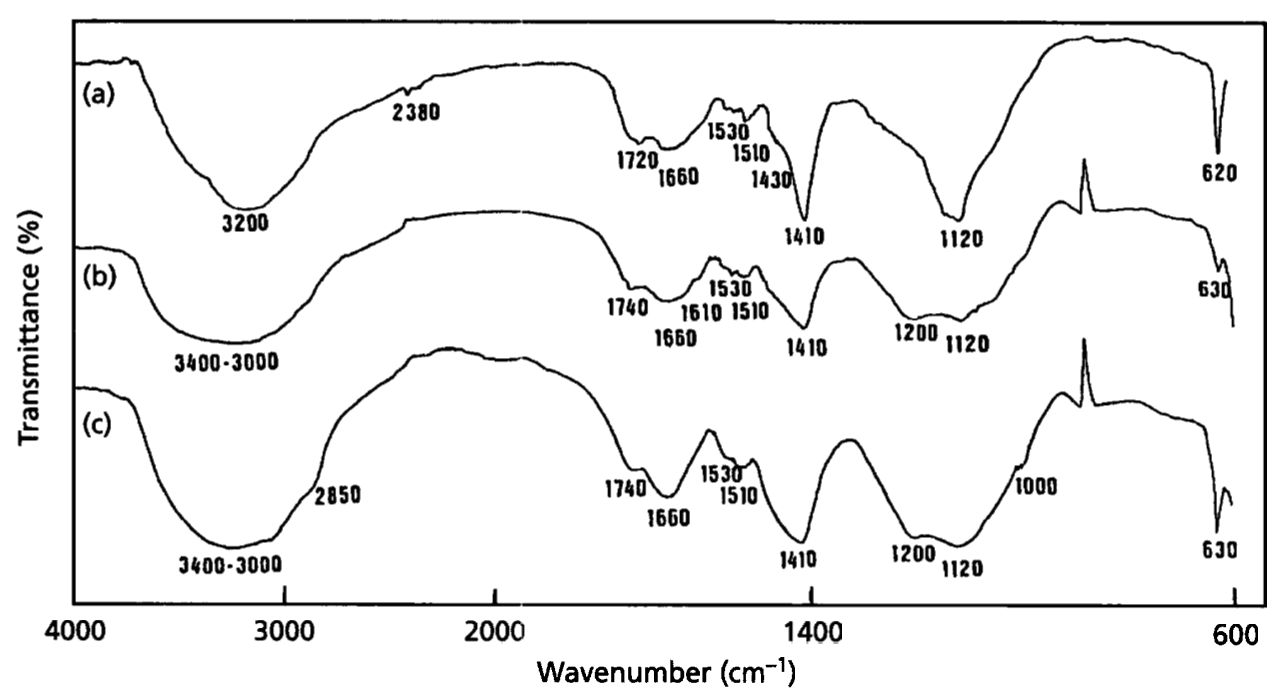

Fig. 4. Infrared spectral analysis of APPL from T. fusca BD25 (a), Streptomyces sp. EC22 (b) and S. viridosporus T7A (c). Culture samples were prepared in $\mathrm{KBr}$ as compressed tablets.

amongst actinomycetes (Trigo \& Ball, 1994), suggesting that this enzyme may be involved not only in degrading lignin (Ramachandra et al., 1988, Trigo \& Ball, 1994), but also in polymerizing the resulting phenolic acids, proteins and sugars to yield a humic acid type polymer, APPL. This suggestion is also supported by the depolymerization-polymerization of lignin reported here for $T$. fusca BD25 and observed in several actinomycete strains (Borgmeyer \& Crawford, 1985; Ball et al., 1990). Finally, infrared spectroscopy confirmed the similarity of APPL to humic acids. These results suggest that the lower levels of lignin degradation by actinomycetes compared to fungi may allow this group of organisms to play a significant role in humification processes in natural soils and composts.

\section{ACKNOWLEDGEMENTS}

C. T. was the recipient of a studentship from JNICT-Portugal and its support is gratefully acknowledged. The authors also thank John Green (Essex University, UK) and Ana Simplicio (IBET, Portugal) for help with chromatographic analysis. This work was partly funded by the NERC (Grant no. GR9 303).

\section{REFERENCES}

Amalfitano, C., Pignalosa, V., Auriemma, L. \& Ramunni, A. (1992). The contribution of lignin to the composition of humic acids from a wheat-straw amended soil during 3 years of incubation pots. J Soil Sci 43, 495-504.

Ball, A. S. \& McCarthy, A. J. (1988). Saccharification of straw by actinomycete enzymes. J Gen Microbiol 134, 2139-2147.

Ball, A. S., Betts, W. B. \& McCarthy, A. J. (1989). Degradation of lignin-related compounds by actinomycetes. Appl Environ Microbiol 55, 159-162.

Ball, A. S., Godden, B., Helvestein, P., Penninckx, M. J. \& McCarthy, A. J. (1990). Lignocarbohydrate solubilisation from straw by actinomycetes. Appl Environ Microbiol 56, 3017-3022.

Betts, W. B., Dart, R. K., Ball, A. S. \& Pedlar, S. L. (1992). Biosynthesis and structure of lignocellulose. In Biodegradation: 
Natural and Synthetic Materials, pp. 139-155. Edited by W. B. Betts. London: Springer-Verlag.

Bollag, J. M., Liu, S. Y. \& Minardi, R. D. (1980). Cross-coupling of phenolic humus constituents and 2,4-dichlorophenol. Soil Sci Soc Am J 44, 52-56.

Bollag, J. M., Liu, S. Y. \& Minardi, R. D. (1981). Enzymatic oligomerization of vanillic acid. Soil Sci Soc Am J 45, 157-163.

Borgmeyer, J. R. \& Crawford, D. L. (1985). Production and characterisation of polymeric lignin degradation intermediates from two different Streptomyces spp. Appl Environ Microbiol 49, 273-278.

Boyd, S. A., Sommers, L. E. \& Nelson, D. W. (1979). Infrared spectra of sewage sludge fractions: evidence for an amide metal binding site. Soil Sci Soc Am J 43, 893-899.

Claus, H. \& Filip, Z. (1988). Behaviour of phenoloxidases in the presence of clays and other soil-related adsorbents. Appl Microb Technol 28, 506-511.

Crawford, D. L. (1978). Lignocellulose decomposition by selected Streptomyces strains. Appl Environ Microbiol 35, 1041-1045.

Crawford, R. L. (1981). Lignin Biodegradation and Transformation. New York: John Wiley \& Sons.

Crawford, D. L., Pometto, A. L., III \& Crawford, R. L. (1983). Lignin degradation by Streptomyces viridosporus: isolation and characterisation of a new polymeric lignin degradation intermediate. Appl Environ Microbiol 45, 898-904.

Crawford, D. L., Pettey, T. M., Thede, B. M. \& Deobald, L. A. (1984). Genetic manipulation of ligninolytic Streptomyces and generation of improved lignin-to-chemical bioconversion strains. Biotechnol Bioeng Symp 14, 241-256.

Donnelly, P. K. \& Crawford, D. L. (1988). Production by Streptomyces viridosporus T7A of an enzyme which cleaves aromatic acids from lignocellulose. Appl Environ Microbiol 54, 2237-2244.

Felbeck, G. T. (1971). Structural hypotheses of soil humic acids. Soil Sci 111, $42-48$.

Filip, Z., Haider, K., Beutelspacher, H. \& Martin, J. P. (1974). Comparisons of IR-spectra from melanins of microscopic soil fungi, humic acids and model phenol polymers. Geoderma 11, 37- 52 .

Fustec, E., Chauvet, E. \& Gas, G. (1989). Lignin degradation and humus formation in alluvial soils and sediments. Appl Environ Microbiol 55, 922-926.

Godden, B., Ball, A. S., Helvenstein, P., McCarthy, A. J. \& Penninckx, M. J. (1992). Towards elucidation of the lignin degradation pathway in actinomycetes. J Gen Microbiol 138, 2441-2448.

Gubler, F., Ashford, A. E., Bacic, A., Blakeney, A. B. \& Stone, B. A. (1985). Release of ferulic acid esters from barley aleurone. II. Characterisation of the feruloyl compounds released in response to $\mathrm{GA}_{3}$. Aust J Plant Physiol 12, 307-317.

Haider, K., Martin, J. P. \& Filip, Z. (1975). Humus biochemistry. In Soil Biochemistry, pp. 195-203. Edited by E. A. Paul \& A. D. McLaren. New York: Marcel Dekker.

Hopwood, D. A., Bibb, M. J., Chater, K. F., Kieser, T., Bruton, C. J., Kieser, H. M., Lydiate, D. J., Smith, C. P., Ward, J. M. \& Schrempf, H. (1985). Genetic Manipulation of Streptomyces. A Laboratory Manual. Norwich: John Innes Foundation.

Katase, T. (1981). The different forms in which p-coumaric acid exists in a peat soil. Soil Sci 131, 271-275.

Kendall, D. N. (1966). Sample preparation procedures. In Applied Infrared Spectroscopy, pp. 145-148. Edited by D. N. Kendall. New York: Reinhold Publishing Co.

Kirk, T. K. \& Farrel, R. L. (1987). Enzymatic 'combustion': the microbial degradation of lignin. Annu Rev Microbiol 41, 465-505.
McCarthy, A. J. (1987). Lignocellulose-degrading actinomycetes. FEMS Microbiol Rev 46, 145-163.

McCarthy, A. J. \& Ball, A. S. (1991). Actinomycete enzymes and activities involved in straw saccharification. In Biodegradation: Natural and Synthetic Materials, pp. 185-199. Edited by W. B. Betts. London: Springer-Verlag.

McCarthy, A. J. \& Broda, P. (1984). Screening for lignin-degrading actinomycetes and characterization of their activity against $\left[{ }^{14} \mathrm{C}\right]$ lignin-labelled wheat lignocellulose. $J$ Gen Microbiol 130, 2905-2913.

McCarthy, A. J., MacDonald, M. J., Paterson, A. \& Broda, P. (1984). Degradation of $\left[{ }^{14} \mathrm{C}\right]$ lignin-labelled wheat lignocellulose by white-rot fungi. J Gen Microbiol 130, 1023-1030.

McCarthy, A. J., Paterson, A. \& Broda, P. (1986). Lignin solubilisation by Thermomonospora mesophila. Appl Microb Biotechnol 24, 347-352.

Martin, J. P. \& Haider, K. (1980). A comparison of the use of phenolase and peroxidase for the synthesis of model humic acidtype polymers. Soil Sci Soc Am J 44, 983-988.

Mason, J. C. (1988). HPLC analysis of solubilisation products from lignocellulose degradation by actinomycetes. Biotechnol Tech 2, 95-100.

Morita, H. (1965). The phenolic acids in organic soils. Can J Biochem 43, $1277-1280$.

Nishitani, K. \& Nevins, D. J. (1988). Enzymatic analysis of feruloylated arabinoxylans (feraxan) derived from Zea mays cell walls I. Purification of novel enzymes capable of dissociating feraxan fragments from Zea mays coleoptile cell wall. Plant Pbysiol 87, 883-890.

Pettit, N. M., Gregory, L. J., Freedman, R. B. \& Burns, R. G. (1977). Differential stabilities of soil enzymes; assay and properties of phosphatase and arylsulphatase. Biochim Biophys Acta 485, 357-366. Pometto, A. L., III \& Crawford, D. L. (1986). Catabolic fate of Streptomyces viridosporus T7A-produced, acid-precipitable polymeric lignin upon incubation with ligninolytic Streptomyces species and Phanerocbaete chrysosporium. Appl Environ Microbiol 51, 171-179.

Pometto, A. L., III \& Crawford, D. L. (1990). High performance liquid chromatography of aromatic fragments from lignin degradation. Methods Enzymol 161, 183-190.

Ramachandra, M., Crawford, D. L. \& Hertel, G. (1988). Characterisation of an extracellular lignin peroxidase of the ligninolytic actinomycete Streptomycete viridosporus. Appl Environ Microbiol 54, 3057-3063.

Russel, J. D., Vaugham, D., Jones, D. \& Fraser, A. R. (1983). An IR spectroscopy study of soil humin and its relationship to other soil humic substances and fungal pigments. Geoderma 29, 1-12.

Senesi, N., Miano, T. M. \& Martin, J.P. (1987). Elemental, functional infrared and free radical characterisation of humic acidtype fungal polymers (melanins). Biol Fertil Soils 5, 120-125.

Shibuya, N. (1984). Phenolic acids and their carbohydrate esters in rice endosperm cell walls. Phytochemistry 23, 2233-2237.

Shimada, M. (1972). Biochemical studies on bamboo lignin and methoxylation in hardwood and softwood lignins. Wood Res 53, 19-65.

Sjoblad, R. D. \& Bollag, J. M. (1981). Oxidative coupling of aromatic compounds by enzymes from soil microorganisms. In Soil Biochemistry, pp. 113-152. Edited by E. A. Paul \& J. N. Ladd. New York: Marcel Dekker.

Skujins, J. J. \& McLaren, A. D. (1969). Assay of urease activity using ${ }^{14} \mathrm{C}$-urea in stored, geologically preserved, and in irradiated soils. Soil Biol Biochem 1, 89-99. 
Stevenson, F. J. \& Goh, K. M. (1971). Infrared spectra of humic acids and related substances. Geochim Cosmochim Acta 35, 471-483.

Suflita, J. M. \& Bollag, J. M. (1980). Oxidative coupling activity in soil extracts. Soil Biol Biochem 12, 177-183.

Trigo, C. \& Ball, A. S. (1994). Production of extracellular enzymes during the solubilisation of straw by Thermomonospora fusca $\mathrm{BD} 25 . J$ Microbiol Biotechnol (in press).
Vicuña, R. (1988). Bacterial degradation of lignin. Enzyme Microb Technol 10, 646-655.

Waksman, S. A. (1967). The Actinomycetes. A Summary of Current Knowledge. New York: Ronald Press Co.

Received 3 March 1994; revised 20 June 1994; accepted 15 July 1994. 